\title{
STUDY OF THE EFFICIENCY OF SQUEEZING MOISTURE-SATURATED PRODUCTS
}

\author{
Gayrat Bahadirov \\ Department of «Theory of Mechanisms and Machines»l \\ instmech@rambler.ru \\ Gerasim Tsoy \\ Department of «Theory of Mechanisms and Machines»l \\ tsoygeran@mail.ru \\ Ayder Nabiev \\ Research laboratory \\ Department of «Theory of Mechanisms and Machines» ${ }^{1}$ \\ a.nabiev@mail.ru \\ ${ }^{1}$ Institute of Mechanics and Seismic Stability of Structures \\ of the Academy of Sciences of the Republic of Uzbekistan \\ 33 Durmen yuli str., Tashkent, Uzbekistan, 100125
}

\begin{abstract}
The leather industry includes many technological machines; a squeezing roller machine is used in many operations, for example, in squeezing, degreasing, and after drum dyeing of a semi-finished leather product.

The paper presents the results of experimental studies obtained by determining the influence of multilayer wet leather semi-finished products with monshons under squeezing on the amount of the moisture extracted. Mathematical dependences of the amount of the moisture extracted, for each layer of a five-layer wet leather semi-finished product on the feed rate between the squeeze rollers and the roller pressure were obtained.

Experimental research is of scientific and practical importance for the development of a technological process for extracting moisture from wet leather semi-finished products used in the tannery, since the quality of the extraction affects the quality of subsequent technological operations, such as leather shaping and splitting.

An experimental study was performed using the method of mathematical statistics, namely, the method of mathematical planning of the experiment.

Mathematical models were obtained for the amount of extracted moisture from five wet leather semi-finished products depending on the rate of their simultaneous feed and the pressure of the squeezing rollers.

The results of the experiment showed that in squeezing a five-layer product, the productivity of the technological process of extracting moisture from wet leather semi-finished products increases by five times in comparison with existing squeezing roller machines.

The use of the results of the experimental study will contribute to a significant reduction in the energy consumption of the squeezing roller machine by simultaneous multi-layer processing of wet leather semi-finished products.

Keywords: semi-finished leather product, monshon, moisture content, multilayer squeezing, residual moisture, technological process, experimental stand, shafts, pressure, productivity.

DOI: $10.21303 / 2461-4262.2021 .001606$
\end{abstract}

\section{Introduction}

In modern industrial conditions, the manufacture of natural leather consists of a number of technological processes: preparatory processes (soaking, liming, pickling, softening, fermentation, degreasing), finishing processes - chemical (tanning), liquid, physicochemical (filling, dyeing, moisture extraction, drying, moisturizing), and mechanical processes (fleshing, shaping, setting, printing, tumbling, breaking, staking, rolling, buffing), surface dyed and other processes.

The study in [1] considers conditions for the primary processing of semi-finished leather products. The studies in [2-4] refer to the improvement of the technology of liquid processing of semi-finished leather products.

The analysis and study of the structure and properties of collagens in semi-finished leather after liquid processing with chemical additives are given in $[5,6]$. 
[7-12] investigate the influence of technological, chemical, and other factors on the physicomechanical, filtration, and qualitative properties of semi-finished leather.

The studies presented in [13-15] are devoted to the improvement of the roller equipment design, including the roller module interaction with the material being processed.

The studies in [16-19] are devoted to the development of the theory of calculation of technological processes for extracting moisture from a semi-finished leather product.

In order to increase the efficiency and productivity of technological process of extracting the excess moisture from wet semi-finished leather products, let's experimentally investigate the influence of such factors as the number of layers of semi-finished leather products and moisture-extracting materials (monshons) on the technological process of moisture extraction from wet semi-finished leather products under their vertical feed on the base plate.

In the leather industry, many technological machines are used, including a roller squeezing machine, which is used in many operations, for example, during pressing, degreasing and after drum dyeing of semi-finished leather products. The quality of the pressing operation determines the quality of subsequent technological operations, such as shaping and splitting of leather semi-finished products.

\section{Materials and methods}

The experiment was performed on a roll stand, where the squeeze rollers were installed horizontally and the base plate was made of a metal sheet $0.005 \mathrm{~m}$ thick, $0.1 \mathrm{~m}$ wide, $0.3 \mathrm{~m}$ long (Fig. 1). One layer of the package consisted of one semi-finished leather product and one layer of moisture-extracting material (monshons) made of LASCH cloth.

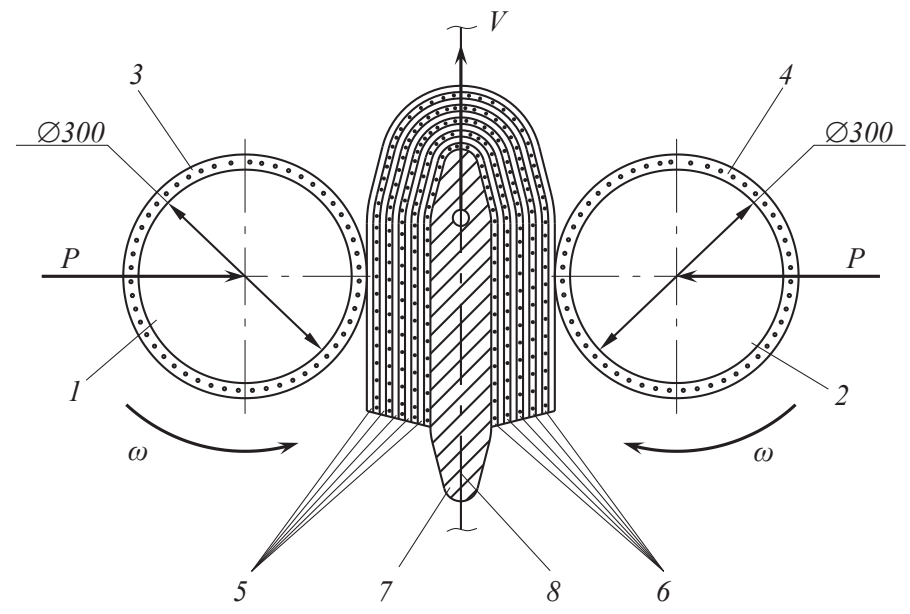

Fig. 1. Scheme of the squeezing five-layer wet leather semi-finished products:

1, 2 - squeeze rollers; 3, 4-BM moisture-extracting materials; 5 - semi-finished leather products; 6 - LASCH moisture-extracting materials; 7 - base plate; 8 - traction chain

Leather material for the experiment was taken from a bovine of medium weight, after chrome tanning, double tanning. According to the International Standard ISO 2588-85, the number of leather samples was selected according to formula $n=0.2 \sqrt{x}$, where $x$ is the number of leather samples for the experiment, taken from a batch of 2500 pcs, so, $n=10$ pcs. From these 10 skin samples, the strips were cut out with a cutter across the backbone line, $0.05 \times 0.25 \mathrm{~m}$ in size; the strips were numbered and assembled into groups of 5 pcs according to the scheme given in [7,20].

The experiment was performed as follows: a $0.004 \mathrm{~m}$ thick strip of LASCH fiber cloth was put on a metal base plate, and then a semi-finished leather product was laid on it, and so on, a layer after layer. Then the stand was switched on, the spring compression was set by calibration to the required pressing force of the squeeze rollers, a rheostat controlled the rate, and a clock-type tachometer TCh 10P controlled the roller rotation frequency. Beforehand, the control skin samples were fed and the spring compression was measured, i. e., its deviation from the setting value. If the deviation exceeded $3 \%$, then the springs were adjusted by tightening the nuts. Then the main 
leather samples were fed. The samples were weighed on a VLTE-500 laboratory balance, with resolution $0.01 \mathrm{~g}$ (ISO-9001) before and after the squeezing.

When processing the results of the experiment, the method of D-optimal planning of the second order was used with Kano planning matrix, since its application provides great accuracy in the regression coefficients estimates. It was taken into account that Kano planning matrix provides a variation of factors at three levels: at the lower level $(-)$, at zero level $(0)$ and at the upper level $(+)$, which is appropriate for this study. On the basis of a priori information, the process of moisture extraction was studied taking into account three factors: $x_{1}$ - roller pressure $P, \mathrm{kN} / \mathrm{m} ; x_{2}-$ feed rate $V, \mathrm{~m} / \mathrm{s}$; the number of layers of leather with monshons was 10; the pressure range was chosen from 32 to $96 \mathrm{kN} / \mathrm{m}$; the rate range of the squeeze rollers was from 0.17 to $0.34 \mathrm{~m} / \mathrm{s}$, and the number of feed replications of a five-layer package of semi-finished leather products was 5 .

In the study, the diameter of the squeeze rollers was $0.3 \mathrm{~m}$, covered with a $0.01 \mathrm{~m}$ thick coating made of BM cloth, one layer of LASCH cloth ( $0.004 \mathrm{~m}$ thick) was bent over the metal base plate; then came a layer of a semi-finished leather product (5 layers of semi-finished leather alternating 5 layers of moisture-extracting material), 10 layers in total.

Before conducting the experiment, the required number of measurements (the number of replications) was selected by the methods of mathematical statistics, which provided the required accuracy.

The working matrix was composed according to the Kano planning matrix for a two-factor experiment. Factors were encoded according to the formula:

$$
x_{i}=\frac{c_{i}-c_{i 0}}{t_{0}},
$$

where $x_{i}$ is the coding of the factors values; $c_{i}, c_{i 0}$ are the natural values of the factor at the current level and at zero level; $t_{0}$ is the natural value of the factor variation interval.

Target functions are approximated by a polynomial:

$$
y=b_{0}+\sum_{i=1}^{k} b_{i} x_{i}+\sum_{i, j=1}^{k} b_{i j} x_{i} x_{j}+\sum_{i=1}^{k} b_{i i} x_{i}^{2},
$$

where $y$ is the amount of extracted moisture in coded form; $b_{0}, b_{i}, b_{i j}, b_{i i}$ are the regression coefficients. The levels and ranges of experimental factor variation are given in Table $\mathbf{1}$.

Table 1

\begin{tabular}{|c|c|c|c|}
\hline \multirow{2}{*}{ Indicator } & \multirow{2}{*}{ Coded value of factors } & \multicolumn{2}{|c|}{ Natural values of factors } \\
\hline & & $x_{1}, \mathrm{kN} / \mathrm{m}$ & $x_{2}, \mathrm{~m} / \mathrm{s}$ \\
\hline Upper level & + & 96 & 0.340 \\
\hline Zero level & 0 & 64 & 0.255 \\
\hline Lower level & - & 32 & 0.170 \\
\hline Variation interval & & 32 & 0.085 \\
\hline
\end{tabular}

Levels and intervals of variation of the experiment factor

After the implementation of the working matrix, the arithmetic mean values were obtained (Tables 2, 3).

The homogeneity of variances was assessed with the Cochran's test at a confidence level of $\alpha=0.95$. Knowing the total number of variance estimates $N$ and the number of degrees of freedom $f=k-1$, let's calculate the homogeneity of variance $G$ from Tables $\mathbf{2}, \mathbf{3}$. Next, let's find $G_{T}=0.358$, at $N=9, f=k-1=5-1=4$. $k$ is the number of parallel experiments.

$$
S_{e r}^{2}=\frac{\sum_{1}^{n}(y-\bar{y})^{2}}{n-1} ; \sum_{1}^{N} S_{i}^{2}=\frac{\sum_{1}^{N} \sum_{1}^{n}(y-\bar{y})^{2}}{N(n-1)} \text {. }
$$




$$
\begin{gathered}
G_{\text {cal } 1}=\frac{S_{\max }^{2}}{\sum_{1}^{N} S_{i}^{2}}=\frac{3.485}{16.3125}=0.2136 ; G_{\text {cal } 2}=\frac{S_{\max }^{2}}{\sum_{1}^{N} S_{i}^{2}}=\frac{5.725}{21.6875}=0.21404 ; \\
G_{\text {cal } 3}=\frac{S_{\max }^{2}}{\sum_{1}^{N} S_{i}^{2}}=\frac{5.9875}{19.5175}=0.3068 ; G_{\text {cal } 4}=\frac{S_{\max }^{2}}{\sum_{1}^{N} S_{i}^{2}}=\frac{8.04}{32.79}=0.2452 ; G_{\text {cal } 5}=\frac{S_{\max }^{2}}{\sum_{1}^{N} S_{i}^{2}}=\frac{5.305}{21.56}=0.2461,
\end{gathered}
$$

where $S_{\max }^{2}$ is the maximal variance; and $\sum S_{i}$ is the sum of all variances.

$G_{\text {cal } 1}=0.2136<G_{T}=0.358 ; G_{\text {cal } 2}=0.2140<G_{T}=0.38 ; G_{\text {cal } 3}=0.30686<G_{T}=0.358 ; G_{\text {cal } 4}=$ $=0.2452<G_{T}=0.358 ; G_{\text {cal }}=0.2461<G_{T}=0.358$. Consequently, the study results are reproducible.

Determine the regression coefficients $b_{0}, b_{i}, b_{i j}, b_{i i}$.

For the first layer of a semi-finished leather product in coded form:

$$
b_{0}=17.9903 ; b_{11}=-1.008 ; b_{1}=4.0255 ; b_{22}=0.8965 ; b_{2}=-2.8823 ; b_{12}=-0.15 \text {. }
$$

For the second layer of a semi-finished leather product in coded form:

$$
b_{0}=17.6748 ; b_{11}=-1.2433 ; b_{1}=3.7255 ; b_{22}=0.9567 ; b_{2}=2.8821 ; b_{12}=0.05 \text {. }
$$

For the third layer of a semi-finished leather product in coded form:

$$
b_{0}=17.4008 ; b_{11}=-1.2036 ; b_{1}=3.4951 ; b_{22}=0.9252 ; b_{2}=-2.8951 ; b_{12}=-0.025 \text {. }
$$

For the fourth layer of a semi-finished leather product in coded form:

$$
b_{0}=16.9529 ; b_{11}=-1.3270 ; b_{1}=3.4166 ; b_{22}=0.8121 ; b_{2}=-2.8666 ; b_{12}=-0.075 \text {. }
$$

For the fifth layer of a semi-finished leather product in coded form:

$$
b_{0}=16.8284 ; b_{11}=-1.2562 ; b_{1}=3.6146 ; b_{22}=0.5938 ; b_{2}=-3.0608 ; b_{12}=0.15 \text {. }
$$

The following coded regression equations were obtained.

For the first layer of semi-finished leather:

$$
y_{1}=17.99026-1.00804 \cdot x_{1}^{2}+0.89146 \cdot x_{2}^{2}+4.0255 \cdot x_{1}-2.8823 \cdot x_{2}-0.15 \cdot x_{1} x_{2} \text {. }
$$

For the second layer of semi-finished leather:

$$
y_{2}=17.6748-1.2433 \cdot x_{1}^{2}+0.9567 \cdot x_{2}^{2}+3.7255 \cdot x_{1}-2.8821 \cdot x_{2}+0.05 \cdot x_{1} x_{2} \text {. }
$$

For the third layer of semi-finished leather:

$$
y_{3}=17.4008-1.2036 \cdot x_{1}^{2}+0.9252 \cdot x_{2}^{2}+3.4951 \cdot x_{1}-2.8951 \cdot x_{2}-0.025 \cdot x_{1} x_{2} \text {. }
$$

For the fourth layer of semi-finished leather:

$$
y_{4}=16.9529-1.3270 \cdot x_{1}^{2}+0.8121 \cdot x_{2}^{2}+3.4166 \cdot x_{1}-2.8666 \cdot x_{2}-0.075 \cdot x_{1} x_{2} \text {. }
$$

For the fifth layer of semi-finished leather:

$$
y_{5}=16.8284-1.2562 \cdot x_{1}^{2}+0.5938 \cdot x_{2}^{2}+3.6146 \cdot x_{1}-3.0608 \cdot x_{2}+0.15 \cdot x_{1} x_{2} \text {. }
$$


Table 2

Experiment planning matrix

\begin{tabular}{|c|c|c|c|c|c|c|c|c|c|}
\hline \multirow{2}{*}{ No. } & \multirow{2}{*}{$P, x_{1}$} & \multirow{2}{*}{$V, x_{2}$} & \multirow{2}{*}{ No. Leth. semi-fin. } & \multicolumn{6}{|c|}{ Measurements results, \% } \\
\hline & & & & $y_{1}$ & $y_{2}$ & $y_{3}$ & $y_{4}$ & $y_{5}$ & $\overline{\boldsymbol{y}}$ \\
\hline \multirow[t]{5}{*}{1} & 0 & 0 & 1 & 18.8 & 19.3 & 17.1 & 17.0 & 16.8 & 17.8 \\
\hline & & & 2 & 17.7 & 18.1 & 17.8 & 16.9 & 16.5 & 17.4 \\
\hline & & & 3 & 17.8 & 18.0 & 18.2 & 16.2 & 15.8 & 17.2 \\
\hline & & & 4 & 19.2 & 16.0 & 17.8 & 16.2 & 15.3 & 16.9 \\
\hline & & & 5 & 17.8 & 15.1 & 17.5 & 16.9 & 16.2 & 16.7 \\
\hline \multirow[t]{5}{*}{2} & + & + & 1 & 19.3 & 20.4 & 21.0 & 18.3 & 16.0 & 19.0 \\
\hline & & & 2 & 19.1 & 20.2 & 20.2 & 14.4 & 17.1 & 18.2 \\
\hline & & & 3 & 18.8 & 17.9 & 17.2 & 14.4 & 17.1 & 18.2 \\
\hline & & & 4 & 16.2 & 19.2 & 16.1 & 16.5 & 17.5 & 17.1 \\
\hline & & & 5 & 18.3 & 16.5 & 18.0 & 15.4 & 15.8 & 16.8 \\
\hline \multirow[t]{5}{*}{3} & - & + & 1 & 11.2 & 10.5 & 11.6 & 12.2 & 9.5 & 11.0 \\
\hline & & & 2 & 11.0 & 10.7 & 11.3 & 9.3 & 11.7 & 10.8 \\
\hline & & & 3 & 10.8 & 11.3 & 10.5 & 11.3 & 9.6 & 10.7 \\
\hline & & & 4 & 9.8 & 11.7 & 13.2 & 8.5 & 9.8 & 10.6 \\
\hline & & & 5 & 10.5 & 10.4 & 7.4 & 9.1 & 9.6 & 9.4 \\
\hline \multirow[t]{5}{*}{4} & - & - & 1 & 17.1 & 17.4 & 16.2 & 16.9 & 16.4 & 16.8 \\
\hline & & & 2 & 17.2 & 16.8 & 17.7 & 15.1 & 16.2 & 16.6 \\
\hline & & & 3 & 16.8 & 17.1 & 14.8 & 17.0 & 15.8 & 16.3 \\
\hline & & & 4 & 17.1 & 17.5 & 13.7 & 16.2 & 15.5 & 16.0 \\
\hline & & & 5 & 17.2 & 16.8 & 13.5 & 15.1 & 16.4 & 15.8 \\
\hline \multirow[t]{5}{*}{5} & + & - & 1 & 25.7 & 25.5 & 26.2 & 21.8 & 23.8 & 24.6 \\
\hline & & & 2 & 25.4 & 25.2 & 24.3 & 19.6 & 24.5 & 23.8 \\
\hline & & & 3 & 24.5 & 26.2 & 24.5 & 20.3 & 20.5 & 23.2 \\
\hline & & & 4 & 23.9 & 25.4 & 20.1 & 23.3 & 21.3 & 22.8 \\
\hline & & & 5 & 23.5 & 24.2 & 19.7 & 22.4 & 23.2 & 22.6 \\
\hline \multirow[t]{5}{*}{6} & + & 0 & 1 & 22.5 & 21.8 & 22.4 & 20.2 & 20.1 & 21.4 \\
\hline & & & 2 & 21.8 & 21.2 & 20.7 & 19.8 & 19.5 & 20.6 \\
\hline & & & 3 & 21.4 & 20.1 & 20.9 & 18.3 & 18.8 & 19.9 \\
\hline & & & 4 & 21.0 & 21.5 & 21.3 & 15.3 & 18.9 & 19.6 \\
\hline & & & 5 & 21.4 & 21.1 & 20.5 & 16.0 & 18.5 & 19.5 \\
\hline \multirow[t]{5}{*}{7} & 0 & + & 1 & 17.4 & 16.8 & 14.5 & 15.5 & 15.8 & 16.0 \\
\hline & & & 2 & 16.9 & 14.5 & 17.0 & 14.7 & 15.9 & 15.8 \\
\hline & & & 3 & 16.7 & 16.5 & 12.6 & 15.1 & 15.6 & 15.3 \\
\hline & & & 4 & 16.1 & 16.4 & 13.2 & 12.3 & 15.0 & 14.6 \\
\hline & & & 5 & 15.8 & 16.2 & 10.5 & 15.3 & 14.2 & 14.4 \\
\hline \multirow[t]{5}{*}{8} & - & 0 & 1 & 15.1 & 14.8 & 11.9 & 11.2 & 11.0 & 12.8 \\
\hline & & & 2 & 14.7 & 14.5 & 11.8 & 11.5 & 10.5 & 12.6 \\
\hline & & & 3 & 12.8 & 13.5 & 14.2 & 9.3 & 12.2 & 12.4 \\
\hline & & & 4 & 12.6 & 12.7 & 11.9 & 10.9 & 12.4 & 12.1 \\
\hline & & & 5 & 12.4 & 12.5 & 11.3 & 11.2 & 11.6 & 11.8 \\
\hline \multirow[t]{5}{*}{9} & 0 & - & 1 & 23.1 & 22.3 & 22.1 & 21.6 & 20.9 & 22.0 \\
\hline & & & 2 & 23.0 & 22.5 & 22.4 & 21.2 & 19.9 & 21.8 \\
\hline & & & 3 & 22.8 & 22.3 & 23.1 & 20.1 & 19.7 & 21.6 \\
\hline & & & 4 & 16.1 & 23.4 & 21.8 & 23.2 & 20.5 & 21.0 \\
\hline & & & 5 & 21.7 & 21.5 & 21.1 & 19.8 & 19.6 & 20.6 \\
\hline
\end{tabular}


Table 3

Experiment planning matrix

\begin{tabular}{|c|c|c|c|c|}
\hline$\sum_{1}^{n}(y-\bar{y})^{2}$ & $S_{e r}^{2}$ & $y_{c a l}$ & $\bar{y}-y_{c a l}$ & $\left(\bar{y}-y_{c a l}\right)^{2}$ \\
\hline 4.38 & 1.095 & 18.0 & 0.2 & 0.04 \\
\hline 1.80 & 0.45 & 17.7 & 0.3 & 0.09 \\
\hline 4.96 & 1.24 & 17.4 & 0.2 & 0.04 \\
\hline 9.96 & 2.49 & 16.95 & 0.05 & 0.025 \\
\hline 3.50 & 0.875 & 16.8 & 0.1 & 0.01 \\
\hline 13.94 & 3.485 & 18.88 & 0.12 & 0.0144 \\
\hline 24.86 & 6.215 & 18.28 & 0.08 & 0.0064 \\
\hline 24.86 & 6.215 & 18.28 & 0.08 & 0.0064 \\
\hline 6.74 & 1.685 & 16.12 & 0.98 & 0.9604 \\
\hline 6.74 & 1.685 & 16.86 & 0.06 & 0.0036 \\
\hline 4.34 & 1.085 & 11.12 & 0.12 & 0.0144 \\
\hline 3.11 & 0.7775 & 10.82 & 0.03 & 0.0009 \\
\hline 1.98 & 0.495 & 10.41 & 0.29 & 0.0841 \\
\hline 13.66 & 3.415 & 9.45 & 1.15 & 1.325 \\
\hline 6.38 & 1.595 & 9.34 & 0.06 & 0.0036 \\
\hline 0.98 & 0.245 & 16.58 & 0.22 & 0.0484 \\
\hline 4.02 & 1.005 & 16.59 & 0.01 & 0.0001 \\
\hline 3.88 & 0.776 & 16.50 & 0.2 & 0.04 \\
\hline 9.04 & 2.26 & 15.02 & 0.98 & 0.9604 \\
\hline 9.57 & 2.3925 & 15.76 & 0.04 & 0.0016 \\
\hline 14.59 & 3.6475 & 24.94 & 0.34 & 0.1156 \\
\hline 22.9 & 5.725 & 23.95 & 0.15 & 0.0225 \\
\hline 23.95 & 5.9875 & 23.54 & 0.41 & 0.1681 \\
\hline 13.36 & 3.34 & 21.99 & 0.81 & 0.6561 \\
\hline 12.18 & 3.045 & 22.98 & 0.38 & 0.1444 \\
\hline 5.5 & 1.375 & 21.0 & 0.38 & 0.1444 \\
\hline 3.66 & 0.915 & 20.16 & 0.44 & 0.1936 \\
\hline 7.06 & 1.765 & 19.52 & 0.38 & 0.1444 \\
\hline 29.44 & 7.34 & 18.73 & 0.87 & 0.7569 \\
\hline 21.22 & 5.305 & 19.18 & 0.32 & 0.1024 \\
\hline 5.14 & 1.285 & 16.0 & 0 & 0 \\
\hline 5.83 & 1.4575 & 15.75 & 0.05 & 0.0025 \\
\hline 10.8 & 2.70 & 15.43 & 0.13 & 0.0169 \\
\hline 12.02 & 3.005 & 14.41 & 0.19 & 0.0361 \\
\hline 21.24 & 5.31 & 14.36 & 0.04 & 0.0016 \\
\hline 13.70 & 3.425 & 12.96 & 0.16 & 0.0256 \\
\hline 14.28 & 3.57 & 12.71 & 0.11 & 0.0121 \\
\hline 14.3 & 3.575 & 12.70 & 0.30 & 0.09 \\
\hline 1.70 & 0.425 & 11.91 & 0.19 & 0.0361 \\
\hline 1.50 & 0.375 & 11.96 & 0.16 & 0.0256 \\
\hline 2.68 & 0.67 & 21.76 & 0.24 & 0.0576 \\
\hline 6.26 & 1.565 & 21.51 & 0.29 & 0.0841 \\
\hline 8.04 & 2.01 & 20.56 & 1.06 & 1.1236 \\
\hline 35.5 & 8.875 & 20.13 & 0.87 & 0.7569 \\
\hline 3.91 & 0.9775 & 20.48 & 0.12 & 0.0144 \\
\hline$\Sigma 65.25$ & $\Sigma 16.31$ & & & $\Sigma 0.4604$ \\
\hline$\sum 86.75$ & $\Sigma 21.69$ & & & $\Sigma 0.4202$ \\
\hline$\sum 78.07$ & $\Sigma 19.52$ & & & $\sum 3.0296$ \\
\hline$\Sigma 131.16$ & $\Sigma 32.79$ & & & $\Sigma 5.5129$ \\
\hline$\sum 86.24$ & $\Sigma 21.56$ & & & $\Sigma 0.3072$ \\
\hline
\end{tabular}


Substituting instead of $x_{1}=(P-64) / 32$, where $P$ is the pressing force of the squeeze rollers and $x_{2}=(V-0.255) / 0.085$, where $V$ is the feed rate of wet semi-finished leather, let's obtain the equation of moisture extracted from the wet leather semi-finished product in percent depending on the pressing force and the rate of wet leather semi-finished product fed between the rotating squeeze rollers.

The hypothesis of the adequacy of the equations obtained was tested with the Fisher criterion at a confidence level of $\alpha=0.95[7,20]$.

$$
F_{c a l}=\frac{S_{a d}^{2}}{S^{2}\{y\}}<F_{T},
$$

where $S_{a d}^{2}$ is the residual variance, or the variance of the adequacy; $S^{2}\{y\}$ is the variance of reproducibility.

The arithmetic mean values of the experiment are shown in Table 3.

From Tables 1-3 let's define $S_{a d}^{2}$ and $S^{2}\{y\}$.

For the first layer of semi-finished leather:

$$
\begin{gathered}
S_{a d 1}^{2}=\frac{\sum_{1}^{N} n \cdot\left(\bar{y}-y_{c a l}\right)^{2}}{N-\frac{(k+2)(k+1)}{2}}=\frac{5 \cdot 0.4604}{3}=0.7673 ; \quad S_{1}{ }^{2}\{y\}=\frac{\sum_{1}^{N} \sum_{1}^{n}(y-\bar{y})^{2}}{N(n-1)}=\frac{65}{9(5-1)}=1.805 \\
F_{\text {cal } 1}=0.425<F_{T}=2.87
\end{gathered}
$$

where $N$ is the total number of experiments; $k$ is the number of factors; $n$ is the number of replications of the experiment; $y_{i}$ is the result of a separate observation; $\bar{y}$ is the arithmetic mean of the result of the experiment; $y_{c a l}$ are the calculated values of the criterion according to the regression equation.

For the second layer of semi-finished leather:

$$
S_{a d 2}^{2}=\frac{5 \cdot 0.4202}{3}=0.7003 ; \quad S_{2}^{2}\{y\}=\frac{86.75}{9(5-1)}=2.41 ; \quad F_{\text {cal } 2}=0.2906<F_{T}=2.87 .
$$

For the third layer of semi-finished leather:

$$
S_{a d 3}^{2}=\frac{5 \cdot 3.0296}{3}=5.0493 ; \quad S_{3}^{2}\{y\}=\frac{78.07}{9(5-1)}=2.1686 ; F_{c a l 3}=2.3284<F_{T}=2.87
$$

For the fourth layer of semi-finished leather:

$$
S_{a d 4}^{2}=\frac{5 \cdot 5.5189}{3}=9.1982 ; \quad S_{4}^{2}\{y\}=\frac{131.16}{9(5-1)}=3.6433 ; F_{c a l 4}=2.5247<F_{T}=2.87 .
$$

For the fifth layer of semi-finished leather:

$$
S_{\text {ad } 5}^{2}=\frac{5 \cdot 0.3072}{3}=0.512 ; \quad S_{5}^{2}\{y\}=\frac{86.24}{9(5-1)}=2.3955 ; F_{\text {cal } 5}=0.2137<F_{T}=2.87 \text {. }
$$

So, the values of $F_{c a l}$ and $F_{T}$ were calculated for five layers of semi-finished leather products after moisture squeezing.

\section{Results}

So, the regression equations can be considered suitable with a $95 \%$ confidence level that in the named form after decoding is:

For the first layer of semi-finished leather:

$$
\Delta W_{1}=21.6798-0.9843 \cdot 10^{-3} P^{2}+123.3854 V^{2}+0.2659 P-93.3094 V-0.0552 P V .
$$


For the second layer of semi-finished leather:

$$
\Delta W_{2}=22.8173-0.1214 \cdot 10^{-2} P^{2}+132.4152 V^{2}+0.2671 P-02.6152 V+0.184 P V .
$$

For the third layer of semi-finished leather:

$$
\Delta W_{3}=22.5086-0.1175 \cdot 10^{-2} P^{2}+128.0595 V^{2}+0.2620 P-99.9582 V-0.00919 P V .
$$

For the fourth layer of semi-finished leather:

$$
\Delta W_{4}=16.2208-0.12959 \cdot 10^{-2} P^{2}+112.4014 V^{2}+0.34295 P-73.4046 V-0.2757 P V .
$$

For the fifth layer of semi-finished leather:

$$
\Delta W_{5}=19.9962-0.12267 \cdot 10^{-2} P^{2}+82.1855 V^{2}+0.2559 P-81.4531 V+0.0552 P V .
$$

Based on the results of the experiment (Fig. 2, $\boldsymbol{a}-\boldsymbol{c}$ ) and mathematical processing, mathematical models of moisture extraction from wet leather semi-finished products were obtained for each layer and for the average of the five layers, depending on the roller pressure and the feed rate.

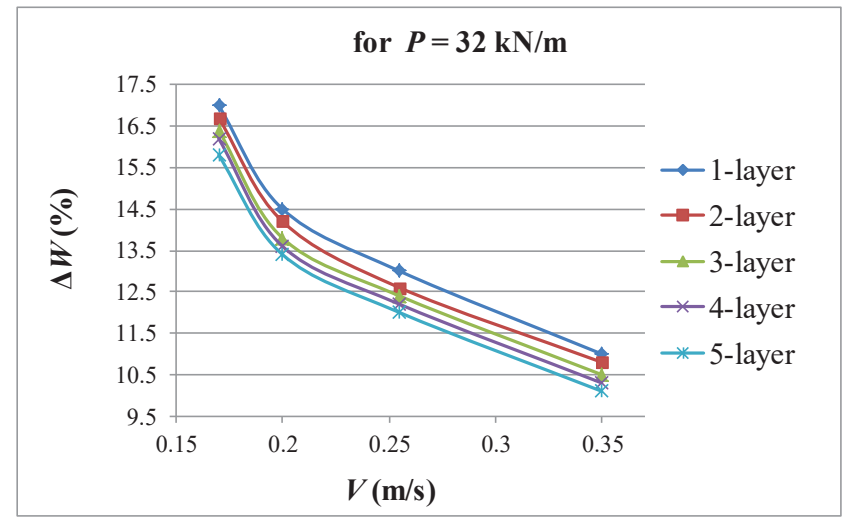

$a$

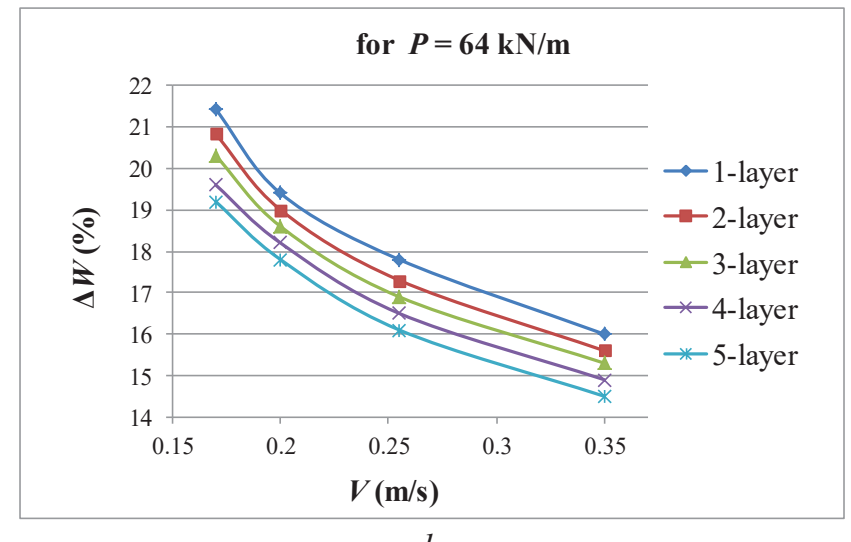

$b$

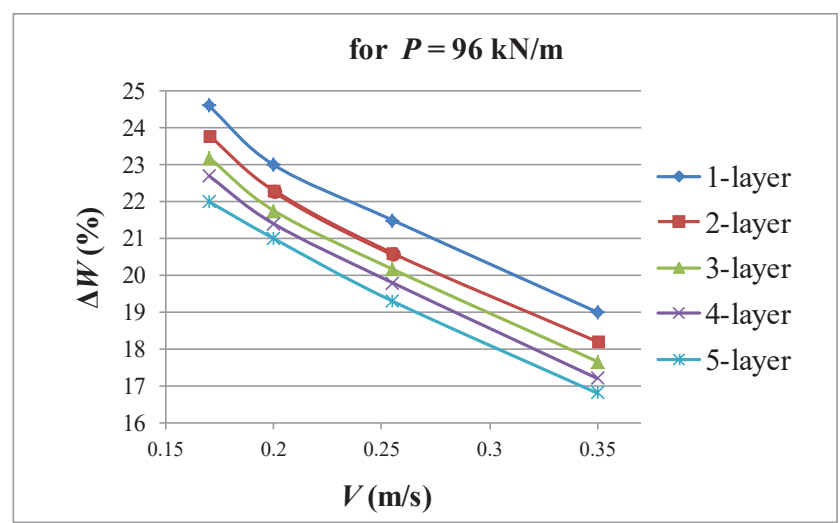

$c$

Fig. 2. Dependence of the amount of the moisture removed $\Delta W$ on the passage velocity $V$ of each of the five layers of semi-finished leather under the pressing force of the squeeze rollers: $a$ - for $P=32 \mathrm{kN} / \mathrm{m} ; b-$ for $P=64 \mathrm{kN} / \mathrm{m} ; c-$ for $P=96 \mathrm{kN} / \mathrm{m}$;

1 - the first layer; 2 - the second layer; 3 - the third layer; 4 - the fourth layer; 5 - the fifth layer of semi-finished leather products 
So, mathematical models of the dependence of the amount of extracted moisture $\Delta W_{1}, \Delta W_{2}$, $\Delta W_{3}, \Delta W_{4}$ and $\Delta W_{5}$ on the pressure of the squeezing rollers and the feed rate for each leather semi-finished product during their five-layer squeezing were obtained.

\section{Discussion of experimental results}

The effectiveness of the results of experimental studies is explained by the fact that the considered method of multilayer squeezing of fibrous materials is combined between a flat press and a roller squeezing.

For the first time, an experimental study of the extraction of moisture from fibrous materials in a multilayer bag is carried out. The research results in comparison with the existing technology for processing fibrous materials show an increase in processing productivity and a decrease in energy consumption for the technological process.

It should be noted that the proposed method can only be used if the dispersion is homogeneous, which is determined using the Cochran criterion.

The disadvantage of this method is that the experiment was carried out with insufficient (production) width of processing leather semi-finished products during their multilayer pressing.

Tables 2, 3 shows the results of the experiment for each of the five layers of leather semi-finished product and their processing according to the method of experiment planning. Data on the definition of the regression equation for the mathematical description of the experimental results are also given. According to Tables 2, 3 the conditions for the reproducibility of the experimental results are determined, as well as the condition for the adequacy of the mathematical model in the form of a regression equation for each layer of the leather semifinished product.

The experimental results show that the difference in the amount of removed moisture between the layers of the leather semi-finished product under the pressing force of the squeezing rollers $P=32 \mathrm{kN} / \mathrm{m}$ (Fig. 2, $\boldsymbol{a}$ ), $P=64 \mathrm{kN} / \mathrm{m}$ (Fig. 2, $\boldsymbol{b}$ ) and $P=96 \mathrm{kN} / \mathrm{m}$ (Fig. 2, ) is less than $1 \%$, which meets the requirement of an allowable deviation (up to $5 \%$ ), established in the technology of extracting excess moisture from wet leather semi-finished products. The amount of moisture extracted during simultaneous squeezing of five layers of semi-finished leather from the outer layer (the first layer) of the semi-finished leather product is more than the amount extracted from the remaining subsequent layers of the semi-finished leather, respectively.

The regression equations obtained for the first layer $\Delta W_{1}$, for the second layer $\Delta W_{2}$, for the third layer $\Delta W_{3}$, for the fourth layer $\Delta W_{4}$, and the fifth layer $\Delta W_{5}$ of the semi-finished leather product fully describe the dependence of the amount of moisture removed from the semi-finished leather product on the feeding speed and the pressing force between the squeezing rollers since the conditions of the experiment were as close as possible to the production ones. The technological parameters used in the experiment, for example, the feeding speed, the pressing force of the squeezing rollers, and others, will be useful in choosing the rational operating modes of the roller squeezing machine.

In the future, to ensure the best efficiency of the multilayer processing method used in the experiment, it is necessary to work out the conditions for an automatic feed of the processed layers of leather semi-finished product onto the transporting base plate and their automatic removal.

For this, in the future, it is planned to manufacture a full-scale model of the machine and the factors will be investigated taking into account the shortcomings that existed at the laboratory stand for squeezing moisture from semi-finished leather products.

\section{Conclusions}

For the investigated sample of semi-finished leather of bovine of medium weight after the tanning process for the shoe upper leather, the maximum moisture content in the belly section reached $73 \%$, and in the butt section it reached $65 \%$. The residual moisture content in the semi-finished leather product after pressing should be 55-60\%, depending on the leather section and function. 
In the case of this experimental study, the residual moisture content should be about $60 \%$. Therefore, it is necessary to extract another $13 \%$ of moisture when squeezing the semi-finished product in a roll stand.

The results of the experiments showed that it is possible to squeeze the moisture out of five layers of a semi-finished leather product simultaneously: under the pressure of the squeeze rollers of $32 \mathrm{kN} / \mathrm{m}$ at a feed rate of up to $0.25 \mathrm{~m} / \mathrm{s}$, the productivity of the technological process of the squeezing machine was five times higher; under the pressure of the squeeze rollers of 64 to $96 \mathrm{kN} / \mathrm{m}$ and at a feed rate of a five-layer leather semi-finished product of $0.34 \mathrm{~m} / \mathrm{s}$, the productivity of the technological process will be about ten times higher, when compared to the productivity of similar squeeze roller machines.

Analysis of experimental results shows that in a five-layer squeezing, the maximum productivity of the roller squeezing machine increases by $500 \%$. With multilayer squeezing of moisture from semi-finished leather products when they are fed bending over the base plate, the labor and energy costs for the technological process of squeezing in a roller squeezing machine are substantially reduced. Therefore, the technological process of moisture squeezing under consideration is more efficient than the method of single-layer squeezing currently used in production on roller pressing machines.

The method of implementing the technological process of moisture extraction can be used by the developers of new designs of technological machines to remove moisture from various materials, for example, in the textile and pulp and paper industries.

\section{References}

[1] Luo, F., Zhong, X., Gao, M., Peng, B., Long, Z. (2020). Progress and mechanism of breaking glycoconjugates by glycosidases in skin for promoting unhairing and fiber opening-up in leather manufacture. A review. Journal of Leather Science and Engineering, 2 (1). doi: https://doi.org/10.1186/s42825-020-00025-0

[2] Danylkovych, A., Bilinskiy, S., Potakh, Y. (2018). Plasticification of leather semifinished chrome tanning using biocatalitic modifier. EUREKA: Physics and Engineering, 1, 12-18. doi: https://doi.org/10.21303/2461-4262.2018.00527

[3] Liu, J., Luo, L., Hu, Y., Wang, F., Zheng, X., Tang, K. (2019). Kinetics and mechanism of thermal degradation of vegetabletanned leather fiber. Journal of Leather Science and Engineering, 1 (1). doi: https://doi.org/10.1186/s42825-019-0010-Z

[4] Danylkovych, A., Lishchuk, V. (2016). An improvement of the technology of manufacturing supple leather through enzymatic plasticizing of a structured semi-finished product. Eastern-European Journal of Enterprise Technologies, 4 (6 (82)), 18-22. doi: https://doi.org/10.15587/1729-4061.2016.73376

[5] Zhang, X., Xu, S., Shen, L., Li, G. (2020). Factors affecting thermal stability of collagen from the aspects of extraction, processing and modification. Journal of Leather Science and Engineering, 2 (1). doi: https://doi.org/10.1186/s42825-020-00033-0

[6] Zhang, Y., Buchanan, J. K., Holmes, G., Mansel, B. W., Prabakar, S. (2019). Collagen structure changes during chrome tanning in propylene carbonate. Journal of Leather Science and Engineering, 1 (1). doi: https://doi.org/10.1186/s42825-019-0011-y

[7] Amanov, A., Bahadirov, G., Amanov, T., Tsoy, G., Nabiev, A. (2019). Determination of Strain Properties of the Leather Semi-Finished Product and Moisture-Removing Materials of Compression Rolls. Materials, 12 (21), 3620. doi: https:// doi.org/10.3390/ma12213620

[8] Mehta, M., Naffa, R., Maidment, C., Holmes, G., Waterland, M. (2020). Raman and atr-ftir spectroscopy towards classification of wet blue bovine leather using ratiometric and chemometric analysis. Journal of Leather Science and Engineering, 2 (1). doi: https://doi.org/10.1186/s42825-019-0017-5

[9] Fan, Q., Ma, J., Xu, Q. (2019). Insights into functional polymer-based organic-inorganic nanocomposites as leather finishes. Journal of Leather Science and Engineering, 1 (1). doi: https://oi.org/10.1186/s42825-019-0005-9

[10] Paiva, R. M., Marques, E. A., da Silva, L. F., Vaz, M. A. (2013). Importance of the surface treatment in the peeling strength of joints for the shoes industry. Applied Adhesion Science, 1 (1), 5. doi: https://doi.org/10.1186/2196-4351-1-5

[11] Kagunyu, A. W., Matiri, F., Ngari, E. (2013). Camel hides: Production, marketing and utilization in pastoral regions of northern Kenya. Pastoralism: Research, Policy and Practice, 3 (1). doi: https://doi.org/10.1186/2041-7136-3-25

[12] Preethi, S., Anumary, A., Ashokkumar, M., Thanikaivelan, P. (2013). Probing horseradish peroxidase catalyzed degradation of azo dye from tannery wastewater. SpringerPlus, 2 (1), 341. doi: https://doi.org/10.1186/2193-1801-2-341

[13] Bahadirov, G. A., Sultanov, T. Z., Abdukarimov, A. (2020). Comparative analysis of two gear-lever differential inter-roller transmission mechanisms. IOP Conference Series: Earth and Environmental Science, 614, 012102. doi: https://oi.org/10.1088/ 1755-1315/614/1/012102 
[14] Mavlonov, T., Akhmedov, A., Saidakhmedov, R., Bakhadirov, K. (2020). Simulation modelling of cold rolled metal strip by asymmetric technology. IOP Conference Series: Materials Science and Engineering, 883, 012194. doi: https://oi.org/ $10.1088 / 1757-899 x / 883 / 1 / 012194$

[15] Bahadirov, G. A., Sultanov, T. Z., Abdukarimov, A. (2020). Kinematic analysis of tooth-lever differential transmission mechanisms. IOP Conference Series: Earth and Environmental Science, 614, 012101. doi: https://oi.org/10.1088/ $1755-1315 / 614 / 1 / 012101$

[16] Khusanov, K. (2020). Stabilization of mechanical system with holonomic servo constraints. IOP Conference Series: Materials Science and Engineering, 883, 012146. doi: https://doi.org/10.1088/1757-899x/883/1/012146

[17] Khusanov, K. (2020). Equations of motion of mechanical systems with nonlinear nonholonomic servoconstraints. IOP Conference Series: Materials Science and Engineering, 869, 072021. doi: https://doi.org/10.1088/1757-899x/869/7/072021

[18] Bahadirov, G., Sultanov, T., Umarov, B., Bakhadirov, K. (2020). Advanced machine for sorting potatoes tubers. IOP Conference Series: Materials Science and Engineering, 883, 012132. doi: https://doi.org/10.1088/1757-899x/883/1/012132

[19] Meistering, M., Stadtler, H. (2020). Stabilized-cycle strategy for a multi-item, capacitated, hierarchical production planning problem in rolling schedules. Business Research, 13 (1), 3-38. doi: https://doi.org/10.1007/s40685-019-0089-3

[20] Farooq, M. A., Nóvoa, H., Araújo, A., Tavares, S. M. O. (2016). An innovative approach for planning and execution of preexperimental runs for Design of Experiments. European Research on Management and Business Economics, 22 (3), $155-161$. doi: https://doi.org/10.1016/j.iedee.2014.12.003 